DOI: $10.17805 /$ zpu.2015.3.27

\title{
Трансформация художественного сознания в век компьютерных технологий
}

\author{
И. Н. ЗАХАРЧЕHKO \\ (РОССИЙСКИЙ ГОСУДАРСТВЕННЫЙ ГУМАНИТАРНЫЙ УНИВЕРСИТЕТ)
}

Компьютерные технологии современного формирующегося информационного общества радикально меняют структуру культурного сознания, в том числе художественного. В условиях роста объема информации встает задача поиска новых методов ее анализа и обобщения. Это свидетельствует о трансформации способов познания мира, изменении характера мышления, рождении современных алгоритмов творческого сознания.

В статье анализируются новые характеристики и ряд новых тенденций художественного сознания, которые проявляются на различных уровнях развития современного искусства. Наиболее ярко их репрезентируют различные ветви технологического и компьютерного искусства. В творческих практиках, использующих технологические возможности информационной эпохи, формируются новые принципы художественного видения, создаются безобъектные произведения искусства, устанавливаются актуальные, соответствующие постмодернистской парадигме мировосприятия возможности художественной коммуникации.

Утверждается, что принципы художественного сознания информационной эпохи возникли в докомпьютерную эру. К середине прошедшего столетия представители некоторых направлений рационально ориентированного искусства (Б. Райли, Х. -Р. Сото, Х. Ле Парк, Ф. Морелле) уже обратились к использованию тех алгоритмов создания искусства, которые позднее лягут в основу компьютерных художественных практик. В качестве примера разбираются теоретические взгляды и творческие практики В. Вазарели, одного из видных представителей европейского оп-арта.

Проведенный анализ показал, что развитие искусства XX в. отражало объективные закономерности эволюции художественного видения. Эпоха повсеместного использования компьютерных технологий была подготовлена логикой структурных трансформаций культурного сознания, в полном объеме обозначившейся в настоящий период.

Ключевые слова: информационная эпоха, художественное сознание, компьютерное искусство, алгоритмическая эстетика, виртуальность, оп-арт, В. Вазарели.

\section{ВВЕАЕНИЕ}

$\mathrm{C}$ овременный этап социокультурного развития неразрывно связан с формированием информационного общества, которое в числе прочего может быть охарактеризовано как эпоха, когда информационные технологии радикально меняют структуру культурного сознания, в том числе художественного. В условиях роста объема информации встает задача поиска новых методов ее анализа и обобщения, что определяет интерес к трансформации способов познания мира, изменению характера мышления, выявлению новых алгоритмов творчества.

Одним из важных проявлений указанных процессов является трансформация художественного сознания, проявляющаяся на различных уровнях развития современного искусства. Рождение новых принципов художественного осмысления мира сегоАня, по утверждению специалистов, наиболее ярко репрезентируют различные ветви технологического и компьютерного искусства, которое может быть определено как «форма искусства, в рамках которой характерные для изобразительного искусства художественные методы и приемы реализуют с использованием цифровых компьютерных технологий» (Ерохин, 2011: 18). В творческих практиках, использующих современные технологические возможности, формируются новые принципы художественного видения, создаются безобъектные произведения искусства, устанавливаются 
актуальные, соответствующие постмодернистской парадигме мировосприятия возможности художественной коммуникации.

Однако анализ некоторых тенденций искусства XX в. позволяет утверждать, что принципы художественного сознания информационной эпохи возникли в докомпьютерную эру. К середине прошедшего столетия представители некоторых направлений рационально ориентированного искусства уже пришли к использованию тех алгоритмов создания искусства, которые позднее легли в основу компьютерных художественных практик. В отечественной исследовательской литературе неоднократно отмечалось, что художественно-эстетические принципы компьютерного искусства и современной художественной коммуникации во многом сформировались на основе тех трансформаций, которые происходили с искусством XX в. на пути движения от классики к авангарду, модернизму и постмодернизму (см., напр.: Маньковская, 2009: 298). Более того, специалисты обращали внимание, что цифровое компьютерное искусство развивалось в общем русле изобразительного (прежде всего европейского и американского) искусства. Его основы были заложены именно на этапе 1960-1970-х годов (см., напр.: Ерохин, 2011: 65-74). Представляется, однако, что дело не только в параллельном развитии ряда тенденций изобразительного и раннего цифрового искусства. Важной исследовательской проблемой является анализ тех алгоритмов художественного сознания, которые предопределили рождение в середине XX в. и новых направлений в развитии искусства, и изобразительных практик с использованием компьютерных технологий. Современное цифровое искусство стало возможным в силу того, что к моменту изобретения первых компьютеров в творческом сознании уже сформировались те грани художественного мышления, которые легли в основу искусства новой культурно-исторической эпохи.

В статье предпринята попытка обосновать на примере оп-арта 1 - одного из направлений рационально ориентированного искусства середины XX в. - рождение в эпоху до широкого внедрения компьютерных технологий художественного мышления, соответствующего культурному сознанию современного информационного общества.

\section{ОСОБЕННОСТИ ХУАОЖЕСТВЕННОГО СОЗНАНИЯ ИНФОРМАЦИОННОЙ ЭПОХИ}

Информационная эпоха в числе прочего может быть охарактеризована как период формирования новой системы мировосприятия, время радикальных трансформаций культурного сознания. Особая роль здесь принадлежит технологиям, развитие которых во многом определило особенности современного искусства. Авторитетный исследователь технологического искусства Ф. Поппер показал, что на протяжении $\mathrm{XX}$ в. наблюдалась не просто эстетизация технологий, но происходил их глубинный синтез с искусством, о чем свидетельствует история фотографии, кинематографа, цветомузыки, кинетической скульптуры и т. А. (Popper, 2007: 2-3). Эксперименты, проводившиеся мастерами немецкого Баухауза и советскими конструктивистами, были выдающимся опытом использования новых материалов и технологий в творческой практике. Их работы свидетельствовали о возможности плодотворной для обеих сторон интеграции технологий и искусства, рождающей новый тип творческого сознания и новые визуальные идеи. Эти процессы совпали с утопическими идеями о создании социально ориентированного искусства, которое можно было бы поставить на службу новым общественным идеалам. Технологии, таким образом, оказались импульсом к развитию современных художественных практик, которые в условиях коммерциализации искусства сохранили изначально присущую ему функцию обретения новых 
смыслов. Актуализация возможностей художественно-образного мышления стимулировала работу интеллекта и воображения в сторону инновационных научно-технологических идей.

Информационная эпоха обозначила новый этап в развитии художественного сознания. Компьютерные технологии формируют творческую деятельность, связанную с организацией визуальных потоков, рождающих ментальный художественный объект. Его восприятие основано на обработке информации и активизации образного мышления. Художественная форма, таким образом, может рассматриваться как такая структура предоставления информации, которая апеллирует к визуально-образному мышлению, обладающему особыми возможностями будить мысль, формировать чуткое отношение к миру (Ерохин, 2011: 45-46).

Компьютерные технологии предполагают новый характер художественного мышления, основанный на тяготении к процессуальности, алгоритмизации, открытости, интерактивности. Именно такие принципы определяют компьютерное искусство, зарождение которого относится к 1950-м годам. Американец Бен Аапаски в 1952 г. впервые использовал катодную трубку осциллографа для создания композиции под названием «электронные абстракции». В 1956 г. он же получил электронное цветное изображение. Вскоре, с 1965 г., эксперименты были продолжены на цифровом компьютере. Их авторами независимо друг от друга почти одновременно стали немецкие художники Ф. Наке и Г. Неес, а также американцы А. М. Нолл, К. Ноултон и Б. Юлеш. С 1980-х годов с ростом популярности, доступности и возможностей персональных компьютеров темпы развития цифрового искусства многократно увеличились. В это время ставятся опыты в компьютерной графике, анимации, лазерных шоу; интенсивно развиваются кинетические виды искусства (там же: 12-15).

В конце XX в. начинается философско-эстетическое осмысление нового феномена. В сферу внимания исследователей входят такие проблемы, как нематериальность, безобъектность цифрового произведения, программируемость его создания, автоматизация процесса художественного творчества и т. А. В числе прочего в это время рождается алгоритмическая эстетика, использующая кибернетическое понятие алгоритма как «точной формулировки последовательности операций, необходимых для выполнения определенной художественной задачи» (Маньковская, 2009: 201). Алгоритмизация мышления отражает одну из важнейших особенностей мировосприятия информационной эпохи.

Подобно тому, как в культурном сознании обозначается ощущение нестабильности, децентричности, утрачивается прежняя устойчивость и определенность, в художественном пространстве рождается и воплощается идея произведения с ускользающей формой, основанного на процессуальности, зависящего от условий восприятия. Наряду с этим меняется и характер художественной коммуникации. Восприятие артобъекта как результат эмоционально-интеллектуальной реакции на особую ментальную структуру предполагает свободное моделирование художественных смыслов, определяет пространственно-временной дискурс, связанный с феноменом виртуальности. Если традиционное искусство, как замечает Н. Б. Маньковская, опиралось на миметический принцип, то в виртуальной реальности он как бы полностью отсутствует. В новой коммуникативной среде «человек не изображает, не выражает и не созерцает нечто, но реально живет и действует в виртуальной жизненной среде по особым правилам игры» (там же: 333). Компьютерные технологии меняют, таким образом, само искусство, пространство его существования и характер восприятия. 
Именно «восприятие, а не артефакт, процесс, а не результат сотворчества оказываются в центре действия» (Маньковская, 2004: 337). Художественные процессы, в свою очередь, выявляют логику трансформации художественного сознания.

\section{ААГОРИТМЫ КОМПЬЮТЕРНОГО ИСКУССТВА \\ В ХУДОЖЕСТВЕННЫХ ПРАКТИКАХ ОП-АРТА}

История творческих практик XX в. свидетельствует о том, что те принципы художественного мышления, которые принято связывать с современным компьютерным искусством, начали формироваться в докомпьютерную эру. Можно, к примеру, вспомнить футуристов начала XX в. По их мнению, обилие информации и ритмы современной жизни не требуют исчерпывающего описания события в искусстве; достаточно знаков или намеков. Их преимущество - в сокращенной дистанции между описанием происходящего (информацией) и эмоцией, итоговым событием в искусстве (Мигунов, 2012: 68).

Важнейшей предпосылкой алгоритмизации ментальных структур явились процессы формирования нового многомерного мировосприятия, определившие релятивизацию культурного и художественного сознания. Свидетельством их проявления в искусстве был отказ - в рамках художественного пространства - от устойчивых пространственно-временных и причинно-следственных критериев, обусловленный потерей реальности как объекта репрезентации. Творческие эксперименты переместились на иные уровни. Они касались новых образцов объемных и плоскостных форм, опытов с особенностями психофизиологического восприятия искусства и художественно-эстетической реакцией индивида. Параллельно первым экспериментам с компьютерными технологиями возникает новое философско-эстетическое понимание искусства, в числе прочего позволяющее осмыслить технологически ориентированное творчество. Искусство XX в., таким образом, выявляет закономерность рождения компьютерных технологий и новых художественных практик.

Важная серия творческих экспериментов, подтверждающих быстрые темпы алгоритмизации и виртуализации художественного сознания до широкого распространения компьютерных технологий, была проведена рационально ориентированными художниками, такими, как Б. Райли, Х.-Р. Сото, Х. Ае Парк, Ф. Морелле, и связанными с ними так называемыми «научными группами», существовавшими в различных странах Европы в 1950-1960-х годах и представлявшими различные ветви оп-арта и кинетизма 2 . Феномен научных групп в европейском искусстве возник в эпоху интереса к новым пространственным мирам, к проникновению ученых в атомную структуру вещества, к физиологическим процессам, к полисенсорности восприятия. Исследуя психофизиологические основы зрительского восприятия, представители рационально ориентированного искусства подходили к реализации первых опытов кибернетического и алгоритмического искусства, разработке принципов современной виртуальной эстетики. Художественные поиски, с их точки зрения, должны быть рациональными и утилитарными, интуитивный творческий процесс должен превратиться в рационально структурированный эксперимент. На этой основе они стремились к превращению изобразительной техники в исследовательскую, искали возможности наделить эстетическим смыслом не произведение в его традиционном понимании, а те виртуальные феномены, оптические иллюзии, которые возникали в результате активизации, следовательно, усовершенствования зрительского восприятия. За этим, как показала видная исследовательница современного искусства К. Милле, стоял «инте- 
рес к существованию невидимых миров, открытых наукой и психологией», и художники во многом стали заниматься «не столько совершенствованием формы, сколько отражением процессуальности, позволяющей художнику воплотить свой замысел в конкретном произведении» (Милле, 1995: 62).

В качестве примера можно обозначить художественные практики одного из лидеров европейского оп-арта В. Вазарели (1906-1997). Его первые самостоятельные эксперименты были связаны со стремлением создать иллюзию движения неподвижной живописной поверхности. Под влиянием идей гештальтпсихологии он работал над проблемой взаимоотношения в художественном пространстве формы и фона. С целью активизации зрительского восприятия он искал варианты становящихся все более абстрактными амбивалентных изображений, принуждающих глаз в поисках границы объектов совершать колебательные движения.

В одном из наиболее известных текстов - статье «Желтый манифест» (1955) — В. Вазарели обозначил основные принципы своего творчества. По его словам, главная цель произведения искусства - создавать әффекты визуального движения на основе использования серийных композиций из геометрических элементов (Theories and documents of contemporary art, 1996: 411). В эпоху бесконечного тиражировании серийных форм «основной интерес составляет уже не образность сама по себе, а ритм ее возникновения, воспроизведения, переплетения и изменения» (Арган, 1999: 663). В современных исследованиях, посвященных В. Вазарели, показано, что «его поиски реальной динамики конвергировали с новейшими достижениями естествознания, где все больше утверждалась картина мира, пребывающего в процессе самосозидания, становления и преобразования форм» (Крючкова, 2010: 299).

В основу творческих экспериментов В. Вазарели лег интерес к проблеме понимаемого в широком смысле движения. Разработка проблемы движения воспринималась им в качестве основы для отказа от произведения искусства прежнего типа и возможности установления динамического взаимодействия «художник - зритель». Язык геометрической абстракции адаптируется к созданию визуальных объектов, провоцирующих глаз совершать неосознанное движение и тем самым определять эмоциональную реакцию зрителя.

Таким образом, В. Вазарели вводит в творческий процесс понятие виртуальности. С 1950-х годов он приходит к созданию картин на основе бинарного орнамента, состоящего из мелких черных и белых квадратов. В. Вазарели трактует их как строительный материал для отображения целостности: «Из этого я делаю вывод, что белые и черные значки, подобно знакомым антиномиям прошлого - таким как “день и ночь”, “ангелы и бесы” или “добро и зло”, - в действительности являются взаимодополняющими факторами, плодотворным андрогином» (цит. по: Хольцхай, 2006: 55). Перспективы художественного воплощения по-настоящему полного знания о мире он видит в синтезе противоположных начал: «Черное и белое, да и нет - вот что будет абсолютно точным бинарным языком кибернетики, при помощи которой можно будет создавать живописный банк данных, хранящийся в разумных электронных компьютерах» (там же). Обоснование в качестве алгоритма творчества ритмической последовательности бинарных оппозиций, которые он позже назовет «пластическими единицами», - вот тот шаг, который делает В. Вазарели в сторону кибернетического мышления и будущего компьютерного искусства.

Найденные на основе научно-экспериментального подхода приемы визуальной стимуляции приводят художника к новым творческим горизонтам, открывая путь 
различным направлениям оп-арта, кинетизма, технологического искусства. Оптическое восприятие для В. Вазарели является основой широкой деятельности воображения, формирующего, в свою очередь, художественно-образное мышление. Используя в своих произведениях элементарные геометрические структуры, он исследует как особенности их сенсорного и интеллектуального восприятия, так и возможности этих структур служить алгоритмической моделью нового творчества.

Здесь же важно отметить, что визуальные эксперименты приводят В. Вазарели к модификации художественного произведения, которое утрачивает прежнюю целостность, статичность, становится проницаемым, открытым для зрительского воздействия. В творчестве художника произведение приобретает качества интерактивности, что свидетельствует о движении в сторону виртуализации как новой парадигмы художественного процесса.

\section{ВЫВОАЫ}

Исследование рационально ориентированных творческих практик ХХ в. показывает, что художественная эволюция отражает объективные процессы трансформации культурного сознания, открывает дорогу компьютерному искусству. Представители рационально ориентированного искусства этого времени впервые вводят в художественное пространство алгоритмы нового мышления, соответствующие мировосприятию информационной эпохи. Подобно тому, как цифровое художественное произведение теряет свой материальный характер, становится динамичным, существует ограниченное время, утрачивает уникальность оригинала, так и работы представителей оптического и кинетического искусства живут только в момент движения, возникающего в пространстве между арт-объектом и глазом зрителя и вызывающего психофизиологическую реакцию в его организме.

Это подтверждает высказанную А. В. Ивановым мысль о том, что «не компьютеризация виртуализирует, а виртуализация компьютеризирует общество» (Иванов, 2002: 204). Эпоха повсеместного использования компьютерных технологий была подготовлена логикой структурных трансформаций культурного сознания, в полном объеме обозначившейся в настоящий период.

\section{ПРИМЕЧАНИЯ}

1 Оп-арт - художественное течение второй половины XX в., ориентировавшееся на достижение оптической иллюзии движения неподвижного художественного объекта путем психофизиологического воздействия на зрителей. Среди его важнейших представителей - В. Вазарели, Б. Райли, Я. Агам, И.-Р. Сото, Х. Ае Парк, Ф. Морелле и др.

2 В 1950-1960-х годах многие художники - представители оп-арта и кинетизма - стали объединяться в группы. В своих манифестах они заявляли о научных подходах к творчеству и разрабатывали по аналогии с группами ученых исследовательские программы по изучению психофизиологических основ восприятия и принципов коммуникации зрителя с художественным произведением. Наиболее активно действующими на европейской художественной сцене были группы Equipo 57 (Испания), Zero ( Германия), Gruppo Enne (Италия), Gruppo Т (Италия), GRAV (Франция), Nul (Нидерланды).

\section{СПИСОК АИТЕРАТУРЫ}

Арган, А. К. (1999) Современное искусство 1770-1970. М. : Искусство. 756 с.

Ерохин, С. В. (2011) Цифровое компьютерное искусство. СПб. : Алетейя. 188 с.

Иванов, А. В. (2002) Виртуализация общества. Версия 2.0. СПб. : Петербургское Востоковедение. 224 с. 
Крючкова, В. А. (2010) Мимесис в эпоху абстракции: Образы реальности в искусстве второй парижской школы. М. : Прогресс-Традиция. 472 с.

Маньковская, Н. Б. (2004) Виртуалистика: художественно-эстетический аспект // Виртуалистика: экзистенциальные и эпистемологические аспекты / ред. Е. А. Мамчур и др. М. : Прогресс-Традиция. 384 с. С. 328-341.

Маньковская, Н. Б. (2009) Феномен постмодернизма. Художественно-эстетический ракурс. М. ; СПб. : Центр гуманитарных инициатив ; Университетская книга. 495 с.

Мигунов, А. С. (2012) Искусство и технология // Научное искусство : материалы I Междунар. науч.-практ. конф. МГУ им. М. В. Аомоносова / ред. В. В. Миронов. М. : МИЭЭ. 288 с. C. 67-69.

Милле, К. (1995) Современное искусство Франции. Минск : Пропилеи. 336 с.

Хольцхай, М. (2006) Виктор Вазарели. 1906-1997: Чистое видение. М. : Taschen/ Арт-родник. $96 \mathrm{c.}$

Popper, F. (2007) From Technological to Virtual Art. Cambridge, Massachusetts, L. : MIT Press. $459 \mathrm{p}$.

Theories and documents of contemporary art: a sourcebook of artist's writings (1996) / ed. K. Stiles, P. Selz. Berkeley and Los Angeles : University of California Press. 1027 p.

Lата поступления: 12.05 .2015 2.

\section{ART IN THE AGE OF COMPUTER TECHNOLOGY: THE QUESTION \\ OF THE TRANSFORMATION OF ARTISTIC CONSCIOUSNESS \\ I. N. ZAKHARCHENKO \\ (RUSSIAN STATE UNIVERSITY FOR THE HUMANITIES)}

The present stage of socio-cultural development is inextricably linked with the development of information society. Computer technologies are radically changing the structure of the cultural consciousness, including art. With a growing amount of information there is a problem of finding new methods of its analysis and synthesis. That leads to the transformation of the ways of learning and discovering the world, to the change in the way of thinking, to the birth of modern algorithms of creative consciousness.

New features of the artistic consciousness are manifested at different levels of development of modern art. Most clearly, they represent different branches of technological and computer art. The creative practice of using technological possibilities of the information age shapes new principles of artistic vision, creates objectless art, and sets current possibilities of artistic communication corresponding to the postmodern worldview paradigm.

Our analysis of some trends in 20th century art suggests that the principles of artistic consciousness of the information age have arisen in the pre-computer era. Some representatives of the rationally oriented art (B. Riley, J.R. Soto, J. le Parc, F. Morellet) have turned to the use of the algorithm for creating art that would form the basis of computer art practices by mid-20th century. In this article, we have focused on the theoretical perspectives and creative practice by V. Vazarely, one of the prominent representatives of European op art (optical art).

We explain the birth of artistic thinking in accordance to the cultural consciousness of the modern information society in the era before the spread of computer technology. The analysis showed that the development of 20th century art reflects the objective laws of the evolution of artistic vision. The era of widespread use of computer technology has been prepared by the logic of the structural transformations of the cultural consciousness, fully identified in today's culture.

Keywords: information society, artistic consciousness, computer art, algorithmic aesthetics, virtual reality, op art, Victor Vasarely.

\section{REFERENCES}

Argan, D. K. (1999) Sovremennoe iskusstvo1770-1970 [Modern art, 1770-1970]. Moscow, Iskusstvo Publ. 756 p. (In Russ.). 
Erokhin, S. V. (2011) Tsifrovoe komp’iuternoe iskusstvo [Digital computer art]. St. Petersburg, Aleteiia. 188 p. (In Russ.).

Ivanov, D. V. (2002) Virtualizatsiia obshchestva. Versiia 2.0. [Virtualization of society. Version 2.0]. St. Petersburg, Peterburgskoe Vostokovedenie. 224 p. (In Russ.).

Kriuchkova, V. A. (2010) Mimesis v epokbu abstraktsii: Obrazy real'nosti v iskusstve vtoroi parizhskoi shkoly [Mimesis in the era of abstraction: images of reality in art of the second Paris school]. Moscow, Progress-Traditsiia Publ. 472 p. (In Russ.).

Man'kovskaia, N. B. (2004) Virtualistika: khudozhestvenno-esteticheskii aspekt [Virtualistics: the artistic and aesthetic aspect]. In: Virtualistika: ekzistentsial'nye $i$ epistemologicheskie aspekty [Virtualistics: existential and epistemological aspects] / ed. by E. A. Mamchur et al. Moscow, Progress-Traditsiia Publ. 384 p. (In Russ.).

Man'kovskaia, N. B. (2009) Fenomen postmodernizma. Khudozhestvenno-esteticheskii rakurs [The phenomenon of postmodernism. Artistic and aesthetic perspective]. Moscow, St. Petersburg, Tsentr gumanitarnykh initsiativ, Universitetskaia kniga Publ. 495 p. (In Russ.).

Migunov, A. S. (2012) Iskusstvo i tekhnologiia [Art and technology]. In: Nauchnoe iskusstvo: Materialy I Mezbdunarodnoi nauchno-prakticheskoi konferentsii. MGU im. M. V. Lomonosova [Scientific Art: Proceedings of the I International Scientific and Practical Conference. MSU]/ ed. by V. V. Mironov. Moscow, MIEE Publ. 288 p. (In Russ.).

Mille, K. (1995) Sovremennoe iskusstvo Frantsii [Contemporary French art]. Minsk, Propilei Publ. 336 p. (In Russ.).

Khol'tskhai, M. (2006) Viktor Vazareli. 1906-1997: Chistoe videnie [Viktor Vazareli. 1906-1997: A Pure vision]. Moscow, Tasshen/Art-rodnik Publ. 96 p. (In Russ.).

Popper, F. (2007) From Technological to Virtual Art. Cambridge, Massachusetts, London, England, MIT Press. 459 p.

Theories and documents of contemporary art: a sourcebook of artist's writings (1996) / ed. K. Stiles and P. Selz. Berkeley, Los Angeles, University of California Press. 1027 p.

Submission date: 12.05.2015.

Захарченко Ирина Николаевна - кандидат исторических наук, доцент кафедры истории и теории культуры отделения социокультурных исследований Российского государственного гуманитарного университета, член АИС. Адрес: 125993, ГСП-3, Москва, Миусская площадь, А. 6. Тел.: +7 (495) 250-68-27. Эл. адрес: inzakh@gmail.com

Zakharchenko Irina Nikolaevna, Candidate of History, Associate Professor, Chair of history and theory of culture, Department of Social and Cultural studies, Russian State University for the Humanities. Postal address: 6 Miusskaya square, 125993 Moscow, Russian Federation. Tel: +7(495) 250-68-27.E-mail: inzakh@gmail.com 